\title{
Do industries lead the stock market in Australia? An examination of the gradual information diffusion hypothesis
}

\author{
Qiongbing $\mathrm{Wu}^{*}$ \\ School of Economics and Finance \\ The University of Western Sydney \\ Locked Bag 1797, Penrith South DC \\ NSW 1797, Australia \\ Abul Shamsuddin \\ Newcastle Business School \\ The University of Newcastle \\ University House, Auckland Street, Newcastle \\ NSW 2300, Australia
}

\begin{abstract}
Using the monthly data for more than 1700 Australian stocks over the period from 1990 to 2009, we extend the work of Hong et al $(J F E, 2007)$ to investigate whether industry portfolio excess returns predict the aggregate market. We find that a few industries, such as General Retailers, Industrial Engineering and Oil Equipment \& Services, significantly lead the market even controlling for well-recognized market predictors. However, we do not find that the ability of an industry to predict the market is closely related to its capacity to forecast economic growth as documented by Hong et al (2007) for the U.S. markets. Instead, we find that the ability of an industry to lead the market is significantly moderated by proxies for investor recognition, providing evidence in support of the gradual-information-diffusion hypothesis. We also find that the predictive power of industry portfolio returns is weaker during periods of economic recession.
\end{abstract}

\section{Draft: 18 November 2010}

JEL classification: G12, G14; E32 and E44.

Keywords:

Asset Pricing, Market Efficiency, Gradual Information Diffusion, Investor Attention, Business Cycle.

*Corresponding author, Tel: 61-2-96859151, Fax: 61-2-96859105, Email: q.wu@uws.edu.au 


\section{Do industries lead the stock market in Australia? An examination of the gradual information diffusion hypothesis}

\section{Introduction}

In this paper we empirically investigate whether industry portfolios lead the aggregate stock market in Australia over the last two decades, and contribute to the literature on the gradual information diffusion proposition by examining whether the slow incorporation of information from industries to the market is a result of investors' limited cognitive capacity or of environmental factors such as business cycle conditions.

Standard asset-pricing models are based on the assumptions that investors are rational and that new information is rapidly incorporated into asset prices in a frictionless and complete market. However, a growing body of research suggests that information gradually diffuses across asset markets due to the attention constraints of investors. According to the gradual information diffusion hypothesis, attention is a scarce cognitive resource (Kahneman 1973; Pashler and Johnston 1998); thus, attention to one task automatically substitutes the cognitive resources from other tasks. Given the immense amount of information available in the markets and the inevitability of limited cognitive capacity, investors can only partially process available information. Consequently, information gradually diffuses across stock markets, and the stock returns exhibit a lead-lag effect or price delay effect (Merton 1987; Hong and Stein 1999; Hirshleifer and Teoh 2003; Peng and Xiong 2006).

Several recent studies have provided empirical evidence in support of the gradual information diffusion hypothesis. Hou and Moskowitz (2005) find that a firm's price delay can be explained by proxies for investor recognition. Hou (2007) finds that the lead-lag relationship 
between large and small firms is primarily driven by the slow diffusion of industry information; and small, less competitive and neglected industries experience a more pronounced lead-lag effect. Barber and Odean (2008) show that attention affects the buying and selling decisions of investors, particularly, it affects buying more than selling because investors who face a buying decision have more difficulty in searching across a larger number of stocks they can potentially buy; therefore, individual investors are more likely to buy attention-grabbing stocks. Using data for firms' customer-supplier links, Cohen and Frazzini (2008) find that news about economically related firms are not promptly incorporated into their stock prices and the extent of late response is more severe in the case of binding attention constraints. Menzly and Ozbas (2010) observe the cross predictability of industry stock returns along customer-supplier links, providing evidence in support of the hypothesis that this gradual information diffusion is attributed to investor specialization and market segmentation.

The paper closely related to ours is Hong et al (2007), who develop a simple two-asset model in a three-period economy based on the assumptions of gradual-information-diffusion. Using U.S. data over the period from 1946 to 2002, they find that it takes two months for the information contained in industries to be completely incorporated into the market index. Hong et al (2007) go further to study an industry's ability to predict market fundamentals, measured by industrial production growth (IPG). They find that the industries that forecast the market also forecast IPG, which is consistent with the notion that the ability of an industry to lead the market is related to its ability to lead economic fundamentals.

We extend Hong et al's (2007) research in the Australian context and empirically test the gradual-information-diffusion hypothesis. Our research is substantially different from Hong et al's (2007) research and contributes to the literature in the following important aspects. 
Firstly, we directly test the gradual-information-diffusion hypothesis by examining whether the slow incorporation of information from industries to market results from investors' attention constraints. Hong et al (2007) have documented that industry returns lead the market returns as the information contained in industries diffuses slowly across the market. However, they do not explain why the ability to predict the market is so different across industries and do not test the gradual information diffusion hypothesis. This study fills this gap by directly testing the relationship between the leading effect of industries and the degree of investors' attention. Given that small, illiquid stocks are more likely to be neglected by investors (Hou and Moskowitz, 2005; Hou, 2007), we construct variables of industry size and liquidity as proxies for investor recognition, and interact these variables with industry portfolio returns to test whether the ability of an industry to predict the aggregate market is related to the industry's level of investor recognition. We find that the predictive power of industries is significantly moderated by the proxies for investor recognition and that the information contained in industries is either captured or mostly offset by industry size or liquidity, providing evidence in support of the gradual-information-diffusion hypothesis.

Secondly, we extend Hong et al's (2007) research to conduct an in-depth analysis for the Australian market by examining whether Australian industries lead the stock market, and whether the ability of an industry to predict the stock market is related to its capacity to forecast market fundamentals. Although Hong et al (2007) have examined similar issues for the eight largest nonUS markets, including Australia, they use raw returns without controlling for market fundamentals in their analyses of these markets. We extend Hong et al (2007)'s sample period and address the issues by controlling for well-recognized market fundamentals such as market dividend yield (Campbell and Shiller, 1988), the term structure (Fama and French, 1989), market 
volatility (Hong, et al, 2007) and changes in the USD/AUD exchange rate (Yao, et al 2005). We find six industries, such as General Retailers, Industrial Engineering, and Oil \& Gas Producers, significantly lead the market. However, we do not find evidence that the ability of an industry to predict the market is closely related to its capacity to forecast economic growth, as documented by Hong et al (2007) for the U.S. markets.

Thirdly, we contribute to the literature on stock behavior over the business cycle by examining whether an industry's ability to predict the aggregate stock market during the expansionary phase of the business cycle differs from that during the recessionary phase. Changes in the behavior of stock returns over the business cycle are well documented in the literature (for example, Chordia and Shivakumar, 2002). Both the quantity and quality of information increase during the economic expansionary period and decrease during the period of contraction (Veldkamp 2005; Brockman et al 2010). We use the Hodrick-Prescott Filter method (Hodrick and Prescott, 1997) to decompose the trend component and the cyclical component of economic activity and construct a dummy variable representing economic contraction. Our results suggest that industries demonstrate weaker predictive power during economic recession.

This paper is structured as follows: Section 2 describes the data sets and the measurement of variables; Section 3 presents the major empirical results of this paper, and Section 4 concludes.

\section{Data and summary statistics}

Our datasets include market information for the market index and for all individual stocks actively traded in Australian Stock Exchange, and information regarding market fundamentals over the period from 1990 to 2009. The data are sourced from Datastream International. We construct the industry portfolios based on the Datastream classification which 
identifies 47 industry sectors. We limit our analyses to equity securities with primary quotes and exclude industry sectors of investment instruments. We also combine life insurance and non-life insurance sectors into one sector as there are only two life insurance stocks and four non-life insurance stocks; eventually we have 37 industry sectors ${ }^{1}$. The description of industries and the number of stocks in each industry sector are presented in Table 1.

\subsection{Measurement of variables}

We have three sets of variables. The first set of variables includes the industry portfolio excess returns and market excess return. Our variable of primary interest is industry portfolio excess return $R_{i t}$. We construct the monthly value-weighted excess return for each industry portfolio as follow:

Industry portfolio excess return: $R_{i, t}=\sum_{j=1}^{n} W_{j, t} R_{j, t}-R f_{t}$, where $R_{j, t}$ is the continuous return on stock $j$ in industry $i$ over the period $t$ (here $t$ is month), $W_{j, t}$ is the weight of stock $j$ in industry $i$ for period $t$ measured by using the ratio of the market capitalization of stock $j$ to the total market capitalization of industry $i$ at the end of period $t-1 . R f_{t}$ is the risk free rate over period t. The risk-free rate is proxied by the 90-day bank accepted bill rate as the T-bill rate is not available over the sample period ${ }^{2}$.

Market excess return: $R M_{t}=\log \left(\frac{P_{t}}{P_{t-1}}\right)-R f_{t}$, where $P_{t}$ is the Datastream market index at the end of period $t, R f_{t}$ is the risk-free rate over the period $t$. The risk-free rate is proxy by the 90 day bank accepted bill rate.

\footnotetext{
${ }^{1}$ Tobacco industry is excluded as it has two stocks only and both have been delisted since 2001 .

${ }^{2}$ Australia has not issued Treasury Bills since 2002 due to government budget surpluses.
} 
The second set of variables includes indicators of market fundamentals and wellrecognized market predictors as control variables:

Economic growth rate: Growth $_{t}=\log \left(\frac{I P_{t}}{I P_{t-1}}\right)$, where $I P_{t}$ is the index of economic activity over period $t$. Since monthly figures for GDP or the Industrial Production Index are not available for Australia, we use the Westpac-Melbourne Institute Coincident Index of Economic Activity as a proxy for GDP. This index is a weighted average of six economic series typically coincident with economic activity, including real retail trade, civilian employment, unemployment, industrial product, non-farm product and real household income. The index provides a more upto-date picture of economic activity than the conventional measures such as GDP.

Market volatility $\mathrm{MVOL}_{t}$ : Market volatility is estimated from a $\operatorname{GARCH}(1,1)$ model of the following form:

$$
\begin{aligned}
& R M_{t}=0.009702+\varepsilon_{t} \\
& h_{t}=0.000145+0.182346 \varepsilon_{t-1}^{2}+0.780746 h_{t-1}
\end{aligned}
$$

In the mean equation, $R M_{t}$ is the rate of return on the Datastream stock market index, $h_{t}$ is the conditional variance of the random error term, $\varepsilon_{t}$. The parameters are estimated employing the maximum likelihood technique on monthly data for February 1973 to December 2009. All parameters have a p-value of less than 0.01 . The forecast variance can be viewed as a weighted average of the constant variance representing the long run average, the lagged return shock and the lagged variance forecast. Unlike historical volatility, forecast volatility from the $\operatorname{GARCH}(1,1)$ model captures the time-varying aspect of volatility and does not require researchers to arbitrarily specify a particular sample period to estimate historical volatility. 
Dividend yield Mdivyt: Dividend yield on the market index is obtained from Datastream. Dividend is based on an anticipated annual dividend and excludes special or once-off dividends. Dividend yield is calculated based on gross dividend including tax credits.

Term structure TERM $M_{t}$ : Term structure is measured as the difference between the tenyear commonwealth government bond rate and the risk-free rate proxied by the 90 -day bank accepted bill rate.

Change in USD/AUD exchange rate $F X_{t}: F X_{t}$ is measured as the percentage change in the USD/AUD exchange rate from the end of period $t-1$ to the end of period $t$.

The third set of variables is the proxies for investor recognition as well as the index of business cycle. We interact each of these variables, respectively, with industry portfolio returns to test whether the predictive power of industry portfolio returns is moderated by investors' attention and business cycle.

Turnover $\mathrm{TO}_{t}$ : Turnover is measured as the ratio of the total value traded for the industry portfolio in period $t$ against the total market capitalization of the industry portfolio at the end of period $\mathrm{t}-1$.

Value traded $V A_{t}: V A_{t}$ is measured as the ratio of the total value traded for the industry portfolio against the total value traded for the whole market in period $t$. This variable measures the relative liquidity of the industry portfolio across the market.

Size: Size $_{t}$ is measured as the ratio of the market capitalization of the industry portfolio at period $t$ against the total market capitalization of all stocks at period $t$.

Bcycle is a dummy variable that takes a value of one when the economy is in cyclical contraction. We decompose the series of Westpac-Melbourne Institute Coincident Index of 
Economic Activity into trend and cyclical components based on the Hodrick-Prescott Filter method (Hodrick and Prescott, 1997), and then construct the dummy variable that takes a value of one when the cyclical component is negative and zero otherwise.

\subsection{Summary statistics}

Table 1 presents the summary statistics for the variables of primary interest. Columns 1 and 2 of Panel A of Table 1 describe the industry portfolio and corresponding industry code. Column 3 of Panel A reports the number of stocks that are used to construct the portfolio return for each industry. In total, we have 1720 actively traded Australian-listed stocks included in our analyses, with the maximum number of 538 stocks for the Mining industry and a minimum of 4 stocks for the Aerospace \& Defense industry. Panel A of Table 1 presents the summary statistics for the monthly excess returns of 37 industry portfolios. The industry portfolio returns vary substantially over the sample period: 28 out of 37 industries report a negative mean excess portfolio returns, with the lowest of -2.91 percent for the Alternative Energy industry and the highest of 0.52 percent for the Food \& Drug Retailers industry. The Mobile Telecommunications industry seems to be most volatile with the highest standard deviation of 18.77 percent while Real Estate Investment Trusts has the lowest of 4.73 percent.

Panel B of Table 1 presents summary statistics for market excess returns, economic growth rates together with those for the control variables, being market volatility, dividend yield, term structure and the change in USD/AUD exchange rate. The mean monthly market excess return over the sample period is 0.017 percent ranging from -14.527 percent to 7.135 percent, while the average monthly economic growth rate is 0.256 percent with the maximum of 1.658 percent and the minimum of -0.678 percent. 
Summary statistics for our investor recognition proxies, industry size and liquidity, are presented in the Appendix. The Australian stock market is dominated by a few major industries. The five largest industries (Banks, Mining, Fixed Line Telecommunications, Industrial Metals \& Mining, and Real Estate Investment Trusts) make up 62 percent of the whole market capitalization, while Banks and Mining industries jointly constitute about 42 percent of the whole market. Conversely, the combined market capitalization of the ten smallest industries only represents 0.786 percent of the whole market. Similarly, the largest industries are heavily traded by the market. The value traded of Banks and Mining industries alone stands for about 46 percent of the value traded of the whole market, whereas the total value traded of the bottom 10 industries only constitutes 0.656 percent. Unlike Value Traded which indicates the relative industry liquidity across the market, Turnover ratio indicates the industry liquidity relative to the industry size. As such, we don't see as much variation in Turnover, across industries, as we do for the other two variables. The Automobile \& Parts industry, whose market capitalization only constitutes 0.024 percent of the whole market, has a lowest mean turnover ratio of 1.668 percent, while the Industrial Metals \& Mining industry reports the highest average turnover ratio of 7.068 percent.

\section{Empirical results}

We conduct our analyses in two stages. In the first stage, we extend Hong et al's (2007) work for Australian market by examining whether industry portfolio excess returns lead the market, and whether the ability of an industry to lead the market is closely related to its capacity to predict economic growth. In the second stage, we examine whether the ability of an industry to predict the market is moderated by investor recognition and business cycle. We utilize the 
Generalized-Method-of-Moments (GMM) techniques for all our analyses to obtain the estimates that are robust to heteroscedasticity and autocorrelation.

\subsection{Industries, market and market fundamentals}

We start by examining whether Australian industries lead the market controlling for wellknown market predictors. More specifically, we estimate the following specification for each of the 37 industry portfolios respectively:

$$
R M_{t}=\alpha_{i}+\beta_{i} R_{i, t-1}+\lambda_{i}^{\prime} X_{t-1}+e_{i, t}
$$

where the subscripts of $i$ and $t$ denote industry and time period, respectively. $R M_{t}$ is the market excess return over month $t, R_{i, t-1}$ is the value-weighted excess return on industry portfolio $i$ over period $t-1 . X$ represents a vector of lagged control variables which include market excess return $R M_{t-1}$, market volatility $M V O L_{t-1}$, market dividend yield $M d i v y_{t-1}$, term structure $T E R M_{t-1}$, and the changes in USD/AUD exchange rate, $F X_{t-1}$. We also run the regression by including lagged returns on all industries simultaneously.

We then estimate the following specification for each of 37 industry portfolios to test whether the ability of an industry to lead the market is related to its ability to forecast market fundamentals:

$$
\text { Growth }_{t}=\gamma_{i}+\chi_{i} R_{i, t-1}+\phi_{i}^{\prime} Z_{t-1}+\eta_{i, t}
$$

where the subscripts of $i$ and $t$ denote industry and time period, respectively. Growth is the continuous growth rate of economic activity index proxied by the Westpac-Melbourne Institute Coincident Index of Economic Activity. $Z$ is the vector of lagged control variables which is the same as $X$ in equation (3) plus the lagged dependent variable Growth ${ }_{t-1}$. Similarly, 
we also estimate the augmented specification by pooling all lagged excess industry portfolio returns into the regression.

When each of the excess industry portfolio returns enters the regression of equation (3) separately, we find that five industries, being Oil Equipments \& Services, Oil \& Gas Producers, Insurance, Industrial Engineering, and General Retailers, significantly lead the market at 5\% level, while Alternative Energy industry leads the market at $10 \%$ level. The two largest industries, Banks and Mining industries, do not lead the market excess return, which is reasonable given that the Australian stock market is dominated by Banks and Mining industries, and therefore the information contained in both industries' stock prices will be immediately captured by the contemporaneous market index. This result is consistent with the finding that the lagged market excess return has no predictive power in all 37 regressions except for those for the Insurance and Oil \& Gas Producers industries. Table 2 presents the coefficient estimates for the primary interest variable, industry portfolio excess returns; the estimates for the control variables are not reported here but are available upon request. Consistent with previous empirical literature (e.g., Campbell and Shiller, 1988; Fama and French, 1989; Hong, et al, 2007), we find that the lagged market volatility, dividend yield and term structure are significant predictors of future market excess returns, while the change in USD/AUD exchange rates has no predictive power.

Since industry returns are contemporaneously correlated, the regression results of equation (3) may be subject to the bias of omitted variables. We then run the regression of equation (3) with an augmented specification by simultaneously including all 37 industry portfolio returns; and the results are reported in Table 3. Table 3 suggests that nine industries, including Alternative Energy, Beverages, Financial Services, Forestry \& Paper, Industrial Engineering, Oil Equipment \& Services, Personal Goods, Real Estate Investment Trusts, and 
Travel \& Leisure, significantly lead the market at 5\% level, while another four industries lead the market at $10 \%$ significance level. The Oil \& Gas Producers industry which leads the market individually loses its significance in predicting the market when all industries are included in the regression.

The results when each of the industry portfolio excess returns enters regression equation (4), separately, show that six industries can significantly predict the future economic growth rate, with Banks, Food Producers, and Mining at 5\% significance level, and Electricity, Industrial Engineering, and Support Services at $10 \%$ level. The estimates for the primary interest variable, industry portfolio excess returns, are reported in Table 4. Of the six industries which significantly lead the market individually, only Industrial Engineering can significantly predict future economic activity. The results ${ }^{3}$ of the augmented specification of equation (4) suggest that thirteen industries can significantly predict future economic growth at $10 \%$ level (of which eight industries are at 5\% significant level). The industries of Electricity, Food Producers, and Support Services, which can significantly predict future economic activity individually, remain significant in the augmented regression. Only five out of the thirteen industries leading the market significantly in the augmented specification of equation (3) can significantly predict future economic growth in the augmented specification of equation (4). Therefore, we are not able to conclude that the ability of an industry to lead the market is closely related to its ability to predict market fundamentals.

Our results are different from Hong et al (2007) who report 18 out of 31 industries lead the market whereas 11 out of 31 industries significantly predict market fundamentals for Australian market. We conjecture that the difference may come from the following aspects:

\footnotetext{
${ }^{3}$ The results are not reported here but available upon request.
} 
Firstly, Hong et al (2007) use the raw returns on the market and 31 industries over the period 1973 to 2002 whereas we analyze the excess returns on both market and 37 industries over the period 1990 to 2009; the basis of industry classification may be slightly different. Secondly, they do not control their analyses for well-known market predictors, while we do. Thirdly, they adopt the growth rate of Industrial Production Index as the proxy for market fundamentals while we use the growth rate of the Westpac-Melbourne Institute Coincident Index of Economic Activity. In contrast to Hong et al (2007) who find that the ability of an industry to predict the market is closely related to its propensity to forecast market fundamentals for the U.S. market, we do not find significant evidence of this close relation for the Australian market. Our findings open up possible avenues for future research into potential sources of the observed industry-market lead-lag relationships, especially in markets outside the U.S., and also make our investigations as set out in the next section more interesting.

\subsection{Impact of investor recognition and business cycle on the leading ability of industries.}

In this section, we investigate whether the ability of an industry to lead the market is moderated by the proxies for investors' recognition and business cycle. We address this issue by sequentially adding, into the specification of equation (3), an interaction term between lagged excess industry portfolio return and the proxies for investor recognition, as well as an interaction term between those returns and the dummy variable of economic recession, The sign of the coefficients of the interaction terms, compared with the sign of the coefficient of the lagged industrial portfolio excess return, will indicate whether the ability of an industry to lead the market is strengthened or weakened by investors' recognition and during periods of economic recession. 
In general, small and illiquid industries are more likely to be neglected by investors; hence we construct three proxies for investor recognition: Size measures the relative size of the industry across the market, Turnover represents the liquidity of the industry while Value Traded indicates the relative liquidity of the industry across the market. The regression results for each industry are not reported here but are available upon request. We find that the six industries which, individually, lead the market lose their significance when the interaction terms between industry portfolio excess return and the proxies for investor recognition are added into the regressions. The interaction terms of twelve industries and Size as well as Turnover, respectively, and of nine industries and Value Traded are statistically significant at 10\% level. The interaction terms mostly report an opposite sign of coefficient to that of the industry portfolio excess return, and drive out the explanatory power of industry portfolio returns. The results indicate that the information contained in the returns of those small, illiquid industries is slowly incorporated into market return while the information content of large and liquid industries, such as Banks and Mining, can be contemporaneously captured by the market. Our findings provide evidence in support of the gradual-information-diffusion hypothesis that the slow information diffusion from industries to the market may result from the lack of investor recognition of these industries. Our finding that small and illiquid industries are more informative in leading the market is also consistent with that of Naes, et al (2010), who investigate the informativeness of U.S. stock market liquidity for the real economy across stocks and find that small and less liquid stocks are more informative.

We next construct the business cycle dummy variable that takes a value of one during periods of economic recession and zero otherwise, we then add the interaction term between 
industry portfolio excess return and the business cycle dummy to the specification of equation (3). We then test whether the predictive power of industry portfolio returns is moderated by business cycle. The full results are not reported in this paper for reason of brevity but are available on request. We find that the coefficient of the interaction term has a negative sign for all industries, 9 of which are statistically significant at $10 \%$ level. Three industries, being Alternative Energy, Insurance, and Oil \& Gas Producers, which have reported a significantly negative coefficient sign for the specification of equation (3), lose their significance in leading the market when the interaction term is introduced. Nine industries can significantly lead the market at $10 \%$ level when the interaction term is included in the regression. The results suggest that the predictive power of industries is significantly moderated by business cycle, and is mostly weakened during periods of economic recession. This finding is consistent with related literature reporting that both the quantity and quality of information decrease during periods of economic contraction (Veldkamp 2005; Brockman et al 2010). Different industries may behave differently during economic recessionary and expansionary periods. Whether the predictive power of industries is time-varying or not is an open topic for future research.

To demonstrate, Table 5 reports the results of regressing the monthly market excess returns on lagged excess returns on Industrial Engineering, lagged control variables and a series of interaction terms. The Industrial Engineering portfolio consists of 25 actively traded stocks, while both its market capitalization and valued traded constitute less than 0.1 percent of the whole market on average over the sample period, compared with over 40 percent for Banks and Mining industries as a whole. As indicated in specification 1 of Table 5, Industrial Engineering portfolio excess return leads the market significantly at $1 \%$ level while the lagged market excess return has little explanatory power. The result in specification 2 of Table 5 suggests that market 
volatility, market dividend yield, and term structure are good predictors of the market, however, their predictive power is driven out once the lagged Industrial Engineering excess return enters the regression, as reported in specification 3 of Table 5. The lagged Industrial Engineering portfolio excess return remains significant at $1 \%$ level in the presence of well-known market predictors, while the Adjusted- $\mathrm{R}^{2}$ increases by more than 100 percent compared to that of specification 2. Specifications 4 to 6 present the results when an interaction term between lagged Industrial Engineering excess return and the proxies for investor recognition, respectively, is added to specification 3 sequentially. The coefficient on Industrial Engineering excess return loses its significance while all three interaction terms significantly lead the market, and the Adjusted- $\mathrm{R}^{2}$ increases by about 25 percent compared to that for specification 3 . The results suggest that the information contained in Industrial Engineering excess return is captured by those proxies for investor recognition. Specification 7 of Table 5 is the result when the interaction term between Industrial Engineering excess return and the dummy variable for economic recession is added into specification 3. The coefficient on the interaction term has a negative sign but is not statistically significant from zero, the lagged Industrial Engineering excess return remains significant in leading the market, although its significance level has declined slightly compared to that for specification 3. The result implies that the predictive power of Industrial Engineering excess return is weakened during the period of economic recession.

In summary, we find a few industries significantly lead the market, however, we do not find evidence that the ability of an industry to predict the market is closely related to its propensity to forecast market fundamentals. Instead, we find that the predictive power of an industry is significantly moderated by the proxies for investor recognition, which provides 
evidence in support of the gradual-information-diffusion hypothesis. We also find that the predictive power of an industry is weakened during periods of economic recession.

\section{Conclusion}

In this study, we extend Hong et al (2007)'s work to empirically investigate three issues. First, we investigate whether Australian industries lead the market and whether the ability of an industry to predict the market is closely related to its propensity to forecast market fundamentals. Using monthly data of 37 industry portfolios consisting of 1720 actively traded Australian stocks over the period of 1990 to 2009 , we find that the excess returns of six industry portfolios significantly lead the market excess return in the individual industry analyses, and 13 industries significantly lead the market when all industries simultaneously enter the regression. However, we do not find evidence that the ability of an industry to predict the market is closely related to its capacity to forecast economic growth.

Second, we examine whether the gradual information diffusion from industries to the aggregate stock market results from investors' attention constraints. We construct variables for industry size and liquidity as proxies for investor recognition and interact these variables with industry portfolio excess returns. We find that the predictive power of industry portfolio excess return is significantly moderated by the proxies for investor recognition, the information contained in the industry portfolio returns is mostly captured or offset by industry size or liquidity. Small and illiquid industries are more informative in leading the markets due to the lack of recognition of investors. Our results provide evidence in support of the gradual-informationdiffusion hypothesis. 
Third, we investigate whether an industry's ability to lead the market is sensitive to business cycle. We construct the dummy variable that takes a value of one during economic contraction, and interact the dummy variable with industry portfolio excess returns. We find that the coefficient of the interaction term mostly has an opposite sign to the coefficient of the industry portfolio excess return, which indicates that, in general, industries demonstrate weaker predictive power during economic recession. Our results confirm the findings of relevant literature that both the quantity and quality of information decrease during periods of economic contraction (Veldkamp 2005; Brockman et al 2010). 


\section{References:}

Barber, B., and Odean, T., 2008. All that glitters: The effect of attention and news on the buying behavior of individual and institutional investors, Review of Finance Studies 21, 785-818.

Brockman, P, Liebenberg, I., and Schutte, M., 2010. Comovement, information production, and business cycle. Journal of Financial Economics, forthcoming.

Campbell, J., Shiller, R., 1988. The dividend-price ratio and expectation of future dividends and discount factors. Review of Financial Studies 1 195-228.

Chordia, T. and L. Shivakumar, 2002. Momentum, Business Cycle, and Time-varying Expected Returns, Journal of Finance 57, 985-1019

Cohen, L., and Frazzini, A., 2008. Economic links and predictable returns. Journal of Finance, 1977-2011.

Fama, E., French, K., 1989. Business conditions and expected returns on stocks and bonds. Journal of Financial Economics 25, 23-49.

Hirshleifer, D., and Teoh, S. H., 2003. Limited attention, information disclosure, and financial reporting, Journal of Accounting and Economics 36, 337-386.

Hong, H., and Stein, J., 1999. A unified theory of underreaction, momentum trading, and overreaction in asset markets, Journal of Finance 54, 2143-2184.

Hong, H., Torous, W., and Valkanov, R., 2007. Do industries lead the stock market?, Journal of Financial Economics, 83, 367-396.

Hou, K., 2007. Industry information diffusion and the lead-lag effect in stock returns, Reviewof Financial Studies 20, 1113-1138.

Hou, K., and Moskowitz, T., 2005. Market frictions, price delay, and the cross-section of expected returns, Review of Financial Studies 18, 981-1020.

Kahneman, D., 1973. Attention and Effort. Prenctice-Hall, Englewood Cliffs, New Jersey.

Menzly, L., and Ozbas, O., 2010. Market segmentation and cross-predictability of returns, Journal of Finance, forthcoming. 
Merton, R., 1987. A simple model of capital market equilibrium with incomplete information, Journal of Finance 42, 483-510.

Naes, R., Skjeltorp, J. A., and Odegaard, B. A., 2010. Stock market liquidity and business cycle. Journal of Finance, forthcoming.

Pashler, H., and Johnston, J., 1998. Attentional limitations in dual-task performance, in Harold Pashler, ed. Attention (Psychology Press, East Essex, UK).

Peng, L., and Xiong, W., 2006. Investor attention, overconfidence, and category learning, Journal of Financial Economics 80, 563-602.

Veldkamp, L., 2005. Slow boom, sudden crash. Journal of Economic Theory 124, 230-257.

Yao, J., Gao, J., and Alles, L., 2005. Dynamic investigation into the predictability of Australian industrial stock returns: Using financial and economic information. Pacific-Basin Finance Journal 13, 225-245. 
Table 1. Summary Statistics.

This table presents summary statistics for the variables of primary interest. Panel A presents the summary statistics for the excess returns of 37 industry portfolios. The excess return is calculated as the valueweighted industry portfolio return in excess of the risk-free rate, proxied by the 90-day bank accepted bill rate. Panel B presents summary statistics for the market fundamental variables. Growth is the continuous growth rate of economic activity, using as a proxy, the Westpac-Melbourne Institute Coincident Index of Economic Activity. RM is the market excess return. Mvol is the implied market volatility estimated using GARCH $(1,1)$ model. Mdivy is the dividend yield on the market index. Term is the term structure measured as the difference between the 10-year government bond yield and the risk-free rate. FX is the change in USD/AUD exchange rate. All variables are from December 1989 to November 2009 except for RM and Growth which are from January 1990 to December 2009. All the data are sourced from Datastream International. The variables are at monthly frequency and are presented in monthly percentage points.

\begin{tabular}{|c|c|c|c|c|c|c|}
\hline \multicolumn{7}{|l|}{ Panel A. Industry portfolio returns } \\
\hline Industry Description & $\begin{array}{c}\text { Industry } \\
\text { Code }\end{array}$ & $\begin{array}{l}\text { No. of } \\
\text { stocks }\end{array}$ & Mean & Std Dev & Max & Min \\
\hline Aerospace \& Defense & AERSP & 4 & -2.78 & 18.66 & 131.59 & -42.55 \\
\hline Alternative Energy & ALTEN & 14 & -2.91 & 14.20 & 61.21 & -78.78 \\
\hline Automobiles \& Parts & AUTMB & 9 & -1.58 & 8.65 & 20.78 & -48.28 \\
\hline Banks & BANKS & 9 & 0.07 & 5.26 & 13.67 & -15.96 \\
\hline Beverages & BEVES & 12 & -0.53 & 5.99 & 15.08 & -30.69 \\
\hline Chemicals & CHMCL & 16 & -0.14 & 6.85 & 28.68 & -29.00 \\
\hline Construction \& Materials & CNSTM & 48 & -0.09 & 5.64 & 16.51 & -33.47 \\
\hline Electricity & ELECT & 18 & -1.18 & 13.19 & 53.41 & -49.52 \\
\hline Electronic \& Electrical Equipments & ELTNC & 21 & -1.35 & 13.34 & 36.24 & -82.64 \\
\hline Financial Services (Sector) & FNSVS & 121 & -0.62 & 6.06 & 15.20 & -27.74 \\
\hline Fixed Line Telecommunications & TELFL & 11 & -0.30 & 10.27 & 65.87 & -48.94 \\
\hline Food \& Drug Retailers & FDRGR & 7 & 0.52 & 5.03 & 13.61 & -15.96 \\
\hline Food Producers & FOODS & 38 & -0.43 & 5.51 & 10.75 & -30.79 \\
\hline Forestry \& Paper & FSTPA & 8 & -0.88 & 7.56 & 17.51 & -25.79 \\
\hline Gas, Water \& Multi-utilities & GWMUT & 6 & 0.02 & 5.45 & 30.48 & -23.85 \\
\hline General Industrials & GNIND & 8 & -0.33 & 5.41 & 19.61 & -29.64 \\
\hline General Retailers & GNRET & 35 & 0.24 & 5.87 & 15.90 & -26.90 \\
\hline Health Care Equipment \& Services & HCEQS & 58 & -0.60 & 5.57 & 11.88 & -24.18 \\
\hline Household Goods \& Home Const. & HHOLD & 16 & -0.78 & 7.29 & 23.34 & -29.49 \\
\hline Industrial Engineering & INDEN & 25 & -0.91 & 8.11 & 22.35 & -39.69 \\
\hline Industrial Metals \& Mining & INDMT & 122 & -0.44 & 7.89 & 21.71 & -47.59 \\
\hline Industrial Transportation & INDTR & 21 & -0.08 & 6.71 & 26.96 & -28.50 \\
\hline Leisure Goods & LEISG & 8 & 0.26 & 8.00 & 30.00 & -36.52 \\
\hline Life Insurance \& non-life & & 6 & & & & \\
\hline insurance & INSUR & & 0.30 & 6.07 & 16.38 & -29.01 \\
\hline Media & MEDIA & 39 & -0.24 & 7.34 & 17.49 & -45.28 \\
\hline Mining & MNING & 538 & 0.08 & 6.25 & 17.24 & -28.35 \\
\hline Mobile Telecommunications & TELMB & 13 & -2.15 & 18.77 & 68.38 & -57.06 \\
\hline Oil \& Gas Producers & OILGP & 124 & 0.08 & 6.09 & 18.01 & -25.68 \\
\hline
\end{tabular}


Table 1. Summary Statistics (continued).

\begin{tabular}{|lcccccc|}
\hline Panel A. Industry portfolio returns (continued) & & & & & \\
Industry & No. of & & & & \\
Industry Description & Code & stocks & Mean & Std Dev & Max & Min \\
Oil Equipment \& Services & OILES & 7 & -0.12 & 9.65 & 18.12 & -65.26 \\
Personal Goods & PERSG & 11 & -0.57 & 10.19 & 33.89 & -67.31 \\
Pharmaceuticals \& Biotechnology & PHARM & 68 & 0.44 & 10.27 & 62.68 & -44.01 \\
Real Estate Investment \& Services & RLISV & 41 & -0.33 & 4.99 & 11.72 & -19.38 \\
Real Estate Investment Trusts & REITS & 56 & -0.45 & 4.73 & 11.92 & -33.72 \\
Software \& Computer Services & SFTCS & 59 & -2.76 & 12.82 & 46.20 & -62.28 \\
Support Services & SUPSV & 74 & -0.48 & 5.65 & 12.55 & -43.38 \\
Technology Hardware \& & & 13 & & & & \\
Equipment & TECHD & & -2.51 & 13.34 & 69.64 & -66.81 \\
Travel \& Leisure & TRLES & 36 & -0.29 & 5.94 & 14.56 & -22.79 \\
\hline Panel B. Market fundamentals variables & & & & & & \\
& & Std & & & & \\
Growth & Mean & Dev & Max & Min & & \\
RM & 0.256 & 0.332 & 1.658 & -0.678 & & \\
MVOL & 0.017 & 3.927 & 7.135 & -14.527 & & \\
Mdivy & 0.195 & 0.109 & 0.842 & 0.080 & & \\
TERM & 3.819 & 0.874 & 7.060 & 2.680 & & \\
FX & 0.702 & 1.362 & 4.510 & -4.990 & & \\
\hline
\end{tabular}


Table 2. Individual industry predictive regressions of market return.

This table presents the estimates on the primary interest variable, lagged industry portfolio excess returns, for regressions of market excess returns on the lagged excess returns of individual industry portfolios and lagged variables representing market fundamentals. The industry codes denote the lagged excess industry portfolio returns that are separately included in the regression specified in equation (3) (for example, INDEN is the value-weighted excess returns on Industrial Engineering portfolio). The variables for market fundamentals included in the regressions are market excess return, the implied market volatility, the dividend yield on the market index, the term structure, and the change in USD/AUD exchange rates. The standard errors are calculated from heteroscedastic-consistent matrix (Robust-White) and are also robust to autocorrelation. NOB refers to number of observations.

\begin{tabular}{|lcccc|lcccc|}
\hline Industry & Estimate & p-value & $\mathbf{R}^{\mathbf{2}}$ & NOB & Industry & Estimate & p-value & $\mathbf{R}^{\mathbf{2}}$ & NOB \\
\hline AERSP & 0.006 & {$[.609]$} & 0.185 & 124 & INDEN & 0.100 & {$[.007]$} & 0.075 & 240 \\
ALTEN & -0.029 & {$[.067]$} & 0.046 & 231 & INDMT & -0.053 & {$[.366]$} & 0.049 & 240 \\
AUTMB & -0.029 & {$[.352]$} & 0.047 & 240 & INDTR & 0.040 & {$[.353]$} & 0.048 & 240 \\
BANKS & 0.018 & {$[.822]$} & 0.044 & 240 & LEISG & 0.019 & {$[.662]$} & 0.081 & 166 \\
BEVES & 0.003 & {$[.962]$} & 0.044 & 240 & INSUR & -0.112 & {$[.043]$} & 0.065 & 240 \\
CHMCL & 0.053 & {$[.313]$} & 0.049 & 240 & MEDIA & -0.024 & {$[.656]$} & 0.045 & 240 \\
CNSTM & 0.096 & {$[.126]$} & 0.053 & 240 & MNING & -0.040 & {$[.610]$} & 0.046 & 240 \\
ELECT & -0.016 & {$[.460]$} & 0.047 & 240 & TELMB & -0.006 & {$[.625]$} & 0.045 & 240 \\
ELTNC & 0.022 & {$[.320]$} & 0.049 & 240 & OILGP & -0.124 & {$[.041]$} & 0.067 & 240 \\
FNSVS & 0.026 & {$[.611]$} & 0.045 & 240 & OILES & 0.077 & {$[.041]$} & 0.104 & 166 \\
TELFL & 0.006 & {$[.844]$} & 0.083 & 165 & PERSG & 0.018 & {$[.549]$} & 0.046 & 240 \\
FDRGR & -0.028 & {$[.618]$} & 0.048 & 196 & PHARM & 0.014 & {$[.526]$} & 0.045 & 240 \\
FOODS & -0.063 & {$[.297]$} & 0.049 & 240 & RLISV & 0.008 & {$[.915]$} & 0.044 & 240 \\
FSTPA & 0.060 & {$[.159]$} & 0.068 & 204 & REITS & 0.098 & {$[.289]$} & 0.052 & 240 \\
GWMUT & -0.012 & {$[.805]$} & 0.044 & 240 & SFTCS & 0.001 & {$[.942]$} & 0.044 & 240 \\
GNIND & -0.028 & {$[.659]$} & 0.045 & 240 & SUPSV & -0.041 & {$[.593]$} & 0.046 & 240 \\
GNRET & 0.125 & {$[.037]$} & 0.064 & 240 & TECHD & -0.011 & {$[.630]$} & 0.045 & 240 \\
HCEQS & 0.004 & {$[.941]$} & 0.044 & 240 & TRLES & -0.004 & {$[.943]$} & 0.044 & 240 \\
HHOLD & -0.035 & {$[.507]$} & 0.047 & 240 & & & & & \\
\hline
\end{tabular}


Table 3. Joint Industry predictive regression of market return.

This table presents the regression results of market excess returns on the lagged excess returns of all industry portfolios and lagged variables representing market fundamentals. The industry codes represent the excess industryl portfolio returns respectively (for example, INDEN is the value-weighted excess returns on Industrial Engineering portfolio). RM is the market excess return. MVOL is the implied market volatility estimated from a GARCH(1,1) model. Mdivy is the dividend yield on the market index. TERM is the term structure measured as the difference of 10-year government bond yield and the risk-free rate. FX is the change in USD/AUD exchange rate. The standard errors are calculated from heteroscedasticconsistent matrix (Robust-White) and are also robust to autocorrelation.

\begin{tabular}{|lccclccc|}
\hline Parameter & Estimate & t-statistic & P-value & Parameter & Estimate & t-statistic & P-value \\
\hline Intercept & -0.071 & -5.348 & {$[.000]$} & INDTR & 0.079 & 1.298 & {$[.194]$} \\
AERSP & 0.023 & 1.812 & {$[.070]$} & LEISG & -0.083 & -1.523 & {$[.128]$} \\
ALTEN & -0.058 & -2.793 & {$[.005]$} & INSUR & -0.114 & -1.835 & {$[.066]$} \\
AUTMB & -0.030 & -0.710 & {$[.478]$} & MEDIA & -0.006 & -0.082 & {$[.935]$} \\
BANKS & 0.106 & 1.088 & {$[.277]$} & MNING & -0.035 & -0.350 & {$[.726]$} \\
BEVES & -0.193 & -2.480 & {$[.013]$} & TELMB & 0.021 & 0.817 & {$[.414]$} \\
CHMCL & -0.014 & -0.268 & {$[.789]$} & OILGP & -0.086 & -1.214 & {$[.225]$} \\
CNSTM & 0.080 & 1.556 & {$[.120]$} & OILES & 0.131 & 2.518 & {$[.012]$} \\
ELECT & 0.046 & 1.449 & {$[.147]$} & PERSG & -0.149 & -3.439 & {$[.001]$} \\
ELTNC & 0.029 & 1.569 & {$[.117]$} & PHARM & 0.011 & 0.242 & {$[.809]$} \\
FNSVS & 0.106 & 2.009 & {$[.045]$} & RLISV & -0.140 & -1.344 & {$[.179]$} \\
TELFL & 0.071 & 1.120 & {$[.263]$} & REITS & 0.246 & 2.780 & {$[.005]$} \\
FDRGR & 0.045 & 0.645 & {$[.519]$} & SFTCS & -0.041 & -0.904 & {$[.366]$} \\
FOODS & 0.002 & 0.030 & {$[.976]$} & SUPSV & -0.065 & -0.767 & {$[.443]$} \\
FSTPA & 0.130 & 3.050 & {$[.002]$} & TECHD & 0.030 & 1.701 & {$[.089]$} \\
GWMUT & 0.074 & 1.235 & {$[.217]$} & TRLES & -0.166 & -2.173 & {$[.030]$} \\
GNIND & -0.037 & -0.734 & {$[.463]$} & MVOL & -13.675 & -4.256 & {$[.000]$} \\
GNRET & 0.126 & 1.817 & {$[.069]$} & Mdivy & 2.581 & 5.605 & {$[.000]$} \\
HCEQS & -0.035 & -0.553 & {$[.580]$} & TERM & 0.883 & 2.418 & {$[.016]$} \\
HHOLD & -0.092 & -1.612 & {$[.107]$} & FX & -0.150 & -1.515 & {$[.130]$} \\
INDEN & 0.139 & 3.382 & {$[.001]$} & RM & -0.088 & -0.261 & {$[.794]$} \\
INDMT & 0.054 & 0.866 & {$[.386]$} & & & & \\
\hline \multicolumn{1}{c}{$R^{2}$} & 0.569 & & & & & & \\
Adjusted R ${ }^{2}$ & 0.345 & & & & & & \\
\hline
\end{tabular}


Table 4. Industry portfolio returns and future economic activity: results of individual regressions

This table presents the estimates of the primary interest variable, lagged industry portfolio excess returns, for regressions of growth rates on lagged excess returns of individual industry portfolios and lagged variables representing market fundamentals. The industrial codes represent the lagged excess industry portfolio returns respectively (for example, INDEN is the value-weighted excess returns on Industrial Engineering portfolio). The variables for market fundamentals included in the regressions are the lagged dependent variable, the market excess return, the implied market volatility, the dividend yield on the market index, the term structure, and the change in USD/AUD exchange rate. The standard errors are calculated from heteroscedastic-consistent matrix (Robust-White) and are also robust to autocorrelation.

\begin{tabular}{|lcccc|ccccc|}
\hline Industry & Estimate & p-value & R2 & NOB & Industry & Estimate & p-value & R2 & NOB \\
\hline AERSP & 0.002 & {$[.478]$} & 0.081 & 124 & INDEN & 0.005 & {$[.077]$} & 0.172 & 240 \\
ALTEN & -0.001 & {$[.409]$} & 0.144 & 231 & INDMT & -0.002 & {$[.654]$} & 0.163 & 240 \\
AUTMB & 0.000 & {$[.929]$} & 0.162 & 240 & INDTR & -0.005 & {$[.123]$} & 0.169 & 240 \\
BANKS & 0.014 & {$[.011]$} & 0.185 & 240 & LEISG & -0.001 & {$[.757]$} & 0.083 & 166 \\
BEVES & -0.004 & {$[.308]$} & 0.166 & 240 & INSUR & -0.001 & {$[.675]$} & 0.163 & 240 \\
CHMCL & 0.001 & {$[.661]$} & 0.163 & 240 & MEDIA & 0.000 & {$[.920]$} & 0.162 & 240 \\
CNSTM & 0.004 & {$[.335]$} & 0.165 & 240 & MNING & -0.010 & {$[.016]$} & 0.176 & 240 \\
ELECT & 0.004 & {$[.051]$} & 0.180 & 240 & TELMB & 0.001 & {$[.588]$} & 0.163 & 240 \\
ELTNC & -0.001 & {$[.480]$} & 0.164 & 240 & OILGP & 0.001 & {$[.924]$} & 0.162 & 240 \\
FNSVS & 0.004 & {$[.267]$} & 0.165 & 240 & OILES & 0.000 & {$[.970]$} & 0.082 & 166 \\
TELFL & 0.001 & {$[.790]$} & 0.084 & 165 & PERSG & 0.002 & {$[.305]$} & 0.165 & 240 \\
FDRGR & -0.001 & {$[.744]$} & 0.078 & 196 & PHARM & -0.003 & {$[.195]$} & 0.171 & 240 \\
FOODS & -0.009 & {$[.034]$} & 0.176 & 240 & RLISV & 0.003 & {$[.663]$} & 0.163 & 240 \\
FSTPA & 0.003 & {$[.408]$} & 0.058 & 204 & REITS & 0.007 & {$[.199]$} & 0.168 & 240 \\
GWMUT & 0.005 & {$[.208]$} & 0.167 & 240 & SFTCS & -0.001 & {$[.549]$} & 0.163 & 240 \\
GNIND & 0.000 & {$[.971]$} & 0.162 & 240 & SUPSV & -0.009 & {$[.057]$} & 0.173 & 240 \\
GNRET & 0.001 & {$[.896]$} & 0.162 & 240 & TECHD & 0.000 & {$[.955]$} & 0.162 & 240 \\
HCEQS & 0.000 & {$[.972]$} & 0.162 & 240 & TRLES & 0.003 & {$[.329]$} & 0.165 & 240 \\
HHOLD & 0.005 & {$[.210]$} & 0.170 & 240 & & & & & \\
\hline
\end{tabular}


Table 5. Lagged Industrial Engineering excess return and market excess return.

This table presents the regressions results of the monthly market excess returns on lagged excess return on Industrial Engineering portfolio and a series of lagged independent variables. RM is the market excess return. INDEN is the value-weighted excess returns on Industrial Engineering portfolio. MVOL is the implied market volatility estimated from a GARCH(1,1) model. Mdivy is the dividend yield on the market index. TERM is the term structure measured as the difference of 10-year government bond yield and the risk-free rate. FX is the change in USD/AUD exchange rate. Size is the industry size measured as the ratio of the market capitalization of the industry portfolio against the total market capitalization of all stocks. TO is the Turnover measured as the ratio of the total value traded for the industry portfolio in period $t$ against the total market capitalization of the industry portfolio at the end of period t-1. VA is the Value Traded measured as the ratio of the total value traded for the industry portfolio against the total value traded for the whole market. Bcycle is the dummy variable that takes a value of one during periods of economic contraction. The sample period is from January 1990 to December 2009. The standard errors are calculated from heteroscedastic-consistent matrix (Robust-White) and are also robust to autocorrelation.

\begin{tabular}{|c|c|c|c|c|c|c|c|}
\hline & 1 & 2 & 3 & 4 & 5 & 6 & 7 \\
\hline \multirow[t]{2}{*}{ Intercept } & 0.001 & -0.017 & -0.014 & -0.012 & -0.011 & -0.012 & -0.015 \\
\hline & {$[.603]$} & {$[.198]$} & {$[.293]$} & {$[.355]$} & [.412] & [.367] & {$[.236]$} \\
\hline \multirow[t]{2}{*}{$\mathrm{RM}$} & -0.030 & 0.065 & -0.019 & -0.055 & -0.045 & -0.043 & -0.023 \\
\hline & {$[.705]$} & [.413] & {$[.825]$} & {$[.509]$} & {$[.593]$} & [.613] & {$[.781]$} \\
\hline \multirow[t]{2}{*}{ INDEN } & 0.120 & & 0.100 & 0.017 & 0.022 & 0.041 & 0.146 \\
\hline & {$[.001]$} & & {$[.007]$} & {$[.754]$} & {$[.670]$} & {$[.363]$} & {$[.008]$} \\
\hline \multirow[t]{2}{*}{ MVOL } & & -5.902 & -4.615 & -3.634 & -4.186 & -4.468 & -3.808 \\
\hline & & {$[.045]$} & {$[.121]$} & {$[.244]$} & {$[.157]$} & [.132] & {$[.225]$} \\
\hline \multirow[t]{2}{*}{ Mdivy } & & 0.651 & 0.555 & 0.466 & 0.457 & 0.496 & 0.577 \\
\hline & & {$[.098]$} & {$[.161]$} & {$[.247]$} & {$[.257]$} & {$[.214]$} & [.143] \\
\hline \multirow[t]{2}{*}{ TERM } & & 0.485 & 0.362 & 0.330 & 0.319 & 0.330 & 0.323 \\
\hline & & {$[.028]$} & {$[.118]$} & {$[.160]$} & {$[.169]$} & {$[.155]$} & {$[.170]$} \\
\hline \multirow[t]{2}{*}{ FX } & & 0.058 & 0.024 & 0.005 & 0.018 & 0.022 & 0.012 \\
\hline & & {$[.556]$} & {$[.811]$} & {$[.961]$} & {$[.855]$} & [.830] & [.907] \\
\hline \multirow[t]{2}{*}{ INDEN *Size } & & & & 0.730 & & & \\
\hline & & & & {$[.086]$} & & & \\
\hline \multirow[t]{2}{*}{ INDEN *TO } & & & & & 1.487 & & \\
\hline & & & & & {$[.046]$} & & \\
\hline \multirow[t]{2}{*}{ INDEN *VA } & & & & & & 0.480 & \\
\hline & & & & & & [.045] & \\
\hline \multirow[t]{2}{*}{ INDEN*Bcycle } & & & & & & & -0.085 \\
\hline & & & & & & & {$[.222]$} \\
\hline $\mathrm{R}^{2}$ & 0.056 & 0.044 & 0.075 & 0.091 & 0.091 & 0.093 & 0.081 \\
\hline Adjusted $\mathrm{R}^{2}$ & 0.048 & 0.024 & 0.051 & 0.064 & 0.064 & 0.065 & 0.053 \\
\hline NOB & 240 & 240 & 240 & 240 & 240 & 240 & 240 \\
\hline
\end{tabular}


Appendix: Summary statistics of industry size and liquidity.

\begin{tabular}{|c|c|c|c|c|c|c|}
\hline \multirow[b]{2}{*}{ Industry } & \multicolumn{2}{|c|}{ Size $(\%)$} & \multicolumn{2}{|c|}{ Turnover $(\%)$} & \multicolumn{2}{|c|}{ Value Trade $(\%)$} \\
\hline & Mean & Std Dev & Mean & Std Dev & Mean & Std Dev \\
\hline Aerospace \& Defense & 0.030 & 0.027 & 3.555 & 7.237 & 0.018 & 0.046 \\
\hline Alternative Energy & 0.018 & 0.023 & 5.860 & 9.046 & 0.018 & 0.032 \\
\hline Automobiles \& Parts & 0.024 & 0.011 & 1.668 & 1.797 & 0.009 & 0.011 \\
\hline Banks & 22.176 & 3.099 & 5.376 & 1.853 & 23.558 & 5.218 \\
\hline Beverages & 3.505 & 1.625 & 4.964 & 2.955 & 2.823 & 1.284 \\
\hline Chemicals & 1.310 & 0.595 & 4.759 & 3.963 & 0.848 & 0.522 \\
\hline Construction \& Materials & 2.196 & 0.399 & 4.135 & 2.480 & 1.642 & 0.648 \\
\hline Electricity & 0.165 & 0.196 & 4.650 & 3.004 & 0.133 & 0.164 \\
\hline Electronic \& Electrical Equipments & 0.100 & 0.050 & 3.109 & 2.029 & 0.072 & 0.077 \\
\hline Financial Services (Sector) & 3.316 & 2.443 & 4.992 & 4.233 & 3.658 & 3.894 \\
\hline Fixed Line Telecommunications & 9.388 & 6.927 & 4.566 & 3.142 & 5.616 & 3.684 \\
\hline Food \& Drug Retailers & 2.351 & 0.609 & 5.346 & 1.944 & 2.223 & 0.898 \\
\hline Food Producers & 0.502 & 0.181 & 3.875 & 2.728 & 0.375 & 0.262 \\
\hline Forestry \& Paper & 0.208 & 0.169 & 4.819 & 3.547 & 0.195 & 0.199 \\
\hline Gas, Water \& Multi-utilities & 2.177 & 1.014 & 4.959 & 2.557 & 2.027 & 1.083 \\
\hline General Industrials & 3.953 & 1.995 & 5.859 & 3.130 & 3.965 & 1.816 \\
\hline General Retailers & 1.911 & 0.677 & 3.439 & 2.518 & 1.238 & 0.810 \\
\hline Health Care Equipment \& Services & 2.003 & 1.216 & 5.279 & 1.881 & 2.164 & 1.607 \\
\hline Household Goods \& Home Const. & 0.266 & 0.075 & 2.826 & 1.673 & 0.158 & 0.141 \\
\hline Industrial Engineering & 0.103 & 0.095 & 3.859 & 3.938 & 0.096 & 0.130 \\
\hline Industrial Metals \& Mining & 5.293 & 2.721 & 7.068 & 2.555 & 7.264 & 4.103 \\
\hline Industrial Transportation & 1.263 & 1.153 & 4.913 & 3.435 & 1.341 & 1.390 \\
\hline Leisure Goods & 0.042 & 0.029 & 3.263 & 2.319 & 0.026 & 0.028 \\
\hline Life Insurance \& non-life insurance & 2.146 & 1.173 & 4.954 & 6.530 & 1.946 & 1.580 \\
\hline Media & 2.771 & 1.162 & 5.087 & 4.982 & 2.572 & 1.414 \\
\hline Mining & 19.869 & 7.685 & 6.468 & 3.254 & 22.379 & 6.667 \\
\hline Mobile Telecommunications & 0.060 & 0.107 & 5.121 & 5.824 & 0.057 & 0.161 \\
\hline Oil \& Gas Producers & 4.191 & 1.131 & 5.819 & 2.735 & 4.712 & 2.453 \\
\hline Oil Equipment \& Services & 0.326 & 0.332 & 3.940 & 3.854 & 0.264 & 0.379 \\
\hline Personal Goods & 0.192 & 0.193 & 4.440 & 4.726 & 0.213 & 0.264 \\
\hline Pharmaceuticals \& Biotechnology & 0.831 & 0.627 & 5.103 & 3.143 & 0.827 & 0.674 \\
\hline Real Estate Investment \& Services & 2.448 & 0.505 & 3.681 & 1.726 & 1.947 & 1.003 \\
\hline Real Estate Investment Trusts & 5.089 & 2.476 & 4.504 & 2.934 & 4.389 & 2.980 \\
\hline Software \& Computer Services & 0.240 & 0.227 & 5.254 & 4.236 & 0.295 & 0.695 \\
\hline Support Services & 1.078 & 0.384 & 3.362 & 1.836 & 0.711 & 0.382 \\
\hline Technology Hardware \& Equipment & 0.052 & 0.034 & 4.998 & 7.836 & 0.069 & 0.127 \\
\hline Travel \& Leisure & 1.923 & 1.131 & 5.768 & 4.545 & 2.383 & 1.952 \\
\hline
\end{tabular}

